\title{
It Looks a Bit Like This: Prototyping in an Academic Library
}

Holt Zaugg

Brigham Young University, holt_zaugg@byu.edu

Elise Silva

Brigham Young University, elise.c.silva@gmail.com

Greg M. Nelson

Brigham Young University, greg_nelson@byu.edu

Cyndee Frasier

Brigham Young University, cynthia_frazier@byu.edu

Follow this and additional works at: https://scholarsarchive.byu.edu/facpub

Part of the Library and Information Science Commons

\section{Original Publication Citation}

Zaugg, H., Silva, E., Nelson, G., \& Frasier, C. (2020). It looks a bit like this: Prototyping in an academic library, Journal of Library Administration, 60(2), 197-213.

\section{BYU ScholarsArchive Citation}

Zaugg, Holt; Silva, Elise; Nelson, Greg M.; and Frasier, Cyndee, "It Looks a Bit Like This: Prototyping in an Academic Library" (2020). Faculty Publications. 3674.

https://scholarsarchive.byu.edu/facpub/3674

This Peer-Reviewed Article is brought to you for free and open access by BYU ScholarsArchive. It has been accepted for inclusion in Faculty Publications by an authorized administrator of BYU ScholarsArchive. For more information, please contact ellen_amatangelo@byu.edu. 


\title{
It Looks a Bit Like This: Prototyping in an Academic Library
}

\author{
Holt Zaugg, Elise Silva, G. M. Nelson \& Cyndee Frasier
}

To cite this article: Holt Zaugg, Elise Silva, G. M. Nelson \& Cyndee Frasier (2020) It Looks a Bit Like This: Prototyping in an Academic Library, Journal of Library Administration, 60:2, 197-213, DOI: $10.1080 / 01930826.2019 .1695473$

To link to this article: https://doi.org/10.1080/01930826.2019.1695473

册 Published online: 03 Feb 2020.

Submit your article to this journal $\asymp$

Q View related articles $\sqsubset$

View Crossmark data $₫$ 


\title{
Pamela Louderback, Library Director, Associate Professor/Library Services, Northeastern State University, Broken Arrow, OK, USA
}

\section{COLUMN EDITOR'S NOTE}

Contributions in this column focus on the closely related topics of strategic planning and assessment in all types of libraries. The articles found herein examine all aspects of planning and assessment including (but not limited to) components, methods, approaches, trends, tools and training.

In the column below, the authors discuss how prototypes can be used in the field of library management. Specifically, the authors examine how prototypes were used at Brigham Young University's (BYU) Harold B. Lee Library to assist in the development of processes, learning materials, services, and physical items. This article explores how a modified process of prototyping was used to inform decision making to better serve BYU's patrons. While this model works for BYU's purposes, the authors note that prototyping may be adapted to meet the needs of other libraries. The five-step process included the identification of a problem or goal, communication among key players, the creation of a prototype, the evaluation and revision of the project, and the final step where successes and failures were celebrated. The authors conclude that prototypes offer a cost-effective and efficient means to revise library processes, to develop their library resources, and to update library services. This process of prototyping offers ongoing insights to continued improvements on library management

\section{It Looks a Bit Like This: Prototyping in an Academic Library}

\author{
Holt Zaugg ${ }^{a}$, Elise Silva ${ }^{b}$, G. M. Nelson ${ }^{c}$, and Cyndee Frasier ${ }^{d}$ \\ ${ }^{a}$ Assessment Librarian, Harold B. Lee Library, Brigham Young University, Provo, UT, USA; ${ }^{b}$ Writing \\ Programs Librarian, Harold B. Lee Library, Brigham Young University, Provo, UT, USA; 'Science \& \\ Engineering Department Chair - Chemical \& Life Sciences Librarian, Harold B. Lee Library, Brigham \\ Young University, Provo, UT, USA; ${ }^{\mathrm{d}}$ Media Center Unit Manager, Harold B. Lee Library, Brigham Young \\ University, Provo, UT, USA
}

\begin{abstract}
Prototyping is an incremental process that facilitates those looking to make changes in products, services, or resources. Originating in industrial fabrication process, prototyping can be adapted by librarians to examine changes made to library services, amenities, and resources. They offer a cost-effective way of trying something new and needed, to ensure that patron needs are met. This article modifies prototyping into a five-step process and reviews five examples where the Lee Library used prototyping to inform library decisions to inform the development of library services, amenities, processes, and resources to better serve its patrons.
\end{abstract}

\section{KEYWORDS}

Prototypes; prototyping; development; strategic planning; service delivery; decision making; evaluation; assessment

\section{Introduction}

Prototyping is commonly found within the design process used in industrial fabricators in the development of products and services (Desrosier, 2011). It serves a creative and 
economic purpose to assist in revisions as the product is developed and improved (Camere \& Bordegoni, 2016; Meier \& Miller, 2016). It also has economic advantages as prototypes can be evaluated for their suitability prior to broader adoption (Medlej, Stuban, \& Dever, 2017). However, prototyping is often thought of only in terms of products and less so in terms of processes, course development, and services. This article examines how prototypes were used within the Lee Library at Brigham Young University (BYU) to assist in the development of processes, learning materials, services, and physical items.

\section{Literature review}

The design process uses prototyping to allow some end users to engage with products and services on a limited scale prior to their full release to the full population for which they are designed (Camere \& Bordegoni, 2016). Using broad-based teams, the prototyping process is driven by waves of convergent and divergent thinking that enables those creating the end product or service to learn from one another (Coleman, 2016; Deitering \& Filar-Williams, 2018). This divergent and convergent thinking includes the examination of the product on a part by part basis and how each part fits into a holistic view of the product or service and the environment where it will be used. It helps the design team to view the product or service from multiple perspectives, including the perspective of those who will be using the product or service (Chasanidou, Gasparini, \& Lee, 2015).

As communication silos are broken down, developers gain a greater understanding, which helps them to consider cultural factors and contexts where the product or service will be used (Coleman, 2016). The goal is to lower costs and increase the quality and utility of the product or service being developed. It promotes risk-taking, openness, curiosity, and perseverance as developers create a prototype, evaluate, and re-create it based on the feedback received (Becksford \& Metko, 2017; Chasanidou et al., 2015; Lopez \& Wright, 2002).

The intent of the prototyping process is to glimpse at the final product and service to determine how it may be improved, before it is finished. The goal is to create a product or service that is an improvement over the last iteration and increasingly helpful. The design process and prototyping follow specific rules and steps to help developers navigate the uncertainty in the design process (Lopez \& Wright, 2002). This effort seeks to situate the prototyping process within an academic library setting by defining steps that were used on specific prototype projects within the Lee Library.

\section{Prototyping model}

There are many models and steps used in prototyping, but any model needs to be adapted to the specific situation. Those using prototyping realize that prototyping fits within a design process for a specific purpose. With this in mind, prototyping processes components have been condensed into five steps. While these work for BYU's purposes, they may be adapted to other situations. They are not one-and-done steps but overlap with each other and may be iterative in the design process. 


\section{Step 1: problem or goal identification}

The process of goal or problem identification is a statement of what a prototype hopes to accomplish. The focus of the goal or problem identification may range from simple, straightforward goals to complex, ill-defined problems, but the process has the central aim of meeting the needs of the end users in ways that improve and bless their lives (Chase, 2017; Coleman, 2016; Howard \& Davis, 2011; Meier \& Miller, 2016). The outcomes of the prototype may result in slight, incremental adjustments or radical changes. For those working on or associated with the prototype, the problem or goal identification step helps to unify efforts to create something that is better than what was previously available. While problem or goal identification is the smallest piece of the prototype pie, it carries the greatest importance as the driver of all prototype activities.

\section{Step 2: communication}

This step is pervasive throughout the entire design and prototype process. If done correctly, it provides openness that breaks down silos between collaborators and stakeholders while inspiring curiosity and enabling perseverance (Becksford \& Metko, 2017). Communication serves as the tool for identifying assumptions, understanding perspectives, and facilitating discussions as prototypes are used to improve the current iteration to its end point (Kohler \& Hochreuter, 2014). It is not a one-and-done conversation but a series of interactions that promote understanding between all those associated with the prototype. With this in mind there are three groups with whom communication is critical-those within the team, stakeholders outside of the team, and the end users.

\section{Within-team communication}

Chasanidou et al. (2015) indicate that team collaboration involves cycles of divergent and convergent thinking as team members seek to understand the problem they wish to solve or the goal they want to reach. It examines previous products and theories to determine how they may be used or altered to inform the development of a new prototype. It may use processes such as persona identification, affinity or experience maps, and service blueprints to better understand the end user and how the final iteration of the prototype will best fit into their lives. The team communication identifies and refines the vision as it acknowledges that no one team member will have all of the answers, but each will contribute to the final success of the prototype (Lynn \& Akgün, 2003). The collective communication of team members provides an efficiency that decreases the likelihood that one decision will wipe out all the work by team members (Neeley, Lim, Zhu, \& Yang, 2013). Communication between team members should also include records of meetings, conversations, and decisions that may be referred to throughout the prototype process (Schrage, 1999).

\section{Outside stakeholders}

Deitering and Filar-Williams (2018) emphasize that all of the overlapping members should have regular meetings and updates on the progress and findings from 
prototypes. This interaction enables the exchange of ideas and ensures that there are no surprises as the prototype moves through each iteration and as findings at each stage influence the next iteration. It is the communication that facilitates a free exchange between those who are, in some way, siloed from one another (Becksford \& Metko, 2017). It also facilitates the understanding of differences in how things are done among each of the stakeholder groups.

\section{End users}

Coleman (2016) advocates for those creating and learning from the prototype to have multiple perspectives that create empathy for how the final iteration of the prototype will fit into the life of the end user. Through observations, interviews, and other methods, prototype developers come to better understand who the end users are and how the final prototype will influence their lives.

\section{Step 3: create the prototype}

With the identification of the goal or problem and the communication channels established, the time has started for the development of a prototype. As mentioned earlier, creation includes examining previous theories and products in a cycle of divergent and convergent thinking that leads toward the development of a prototype. It is the start of the largest piece of the prototype pie, as the prototype is repeatedly adjusted and improved in the cycle of creation, assessment, and revision. This step has many facets, but we emphasize only four.

\section{Framework}

The framework provides the parameters for developing the actual prototype. It is often co-designed by the design team with input from stakeholders and end users (Schrage, 1999). It allows for the identification and elimination of errors that may hinder the prototyping process (Ficzere, Borbás, \& Török, 2013). The framework helps to decide how far each prototype will move the design process.

\section{Know users}

Knowledge of end users is a critical component of the prototype or model creation. As mentioned earlier, it uses a wide variety of processes to get to know the end user better and to understand how they go about doing things (Chasanidou et al., 2015).

\section{Sufficient pieces}

In this part of the prototype, designers decide if parts of the final product or processes are prototyped and assessed before being put into a whole product or process or if a more complete version of the finished project or process will be used. The intent is that there are sufficient pieces to the prototype that allow the end user to use and inform 
designers on what works well; what needs to be changed or eliminated; and how the parts fit together and influence the final product.

\section{Avoid perfectionism}

The intent of a prototype is to provide something that enables users to see, evaluate, and refine the prototype. It is better to have multiple iterations of prototypes that learn and build on one another rather than seeking to have a complete, perfect prototype, although some prototypes may be very close to the final version (Desrosier, 2011; Lopez \& Wright, 2002; Neeley et al., 2013).

\section{Step 4: evaluate and revise}

A key part of the prototype process is to evaluate and revise the prototype. The evaluation of the prototype is the diagnostic process that identifies if the design has met key outcomes by indicating what parts of the prototype are a success and what additional revisions are needed, if any (Desrosier, 2011; Kohler \& Hochreuter, 2014; Lopez \& Wright, 2002). The intent is to make frequent small evaluations to influence the final design rather than one large evaluation (Meier \& Miller, 2016). The evaluation seeks to identify changes as early as possible to facilitate any needed changes (Ficzere et al., 2013). Once the prototype is started, this is the iterative process that leads the designers through the twists and turns, resulting in the final product.

\section{Step 5: celebrate success and failure}

A culture of prototyping is helpful for a library interested in improving spaces, services, items, and processes. This culture celebrates successes and failures equally because they serve the same purpose. A success indicates that the prototype was a positive step in improvement. A failure provides insights on how the next prototype can improve. They both promote a culture of prototyping that engenders continual improvement and innovation.

\section{Library prototype examples}

From here these steps are applied to understand prototyping efforts within the Lee Library. The goal of this section is to provide examples of how and where prototypes were used within an academic library to improve the library services, spaces, and processes. The examples discussed include the development of new independent study carrels, the location and configuration of a combined circulation/help desk, the change in how the library's DVD collection was promoted and displayed, the development of an online tutorial for library instruction, and the processes used to evaluate a library collection.

\section{Independent study desks}

The independent study desks (ISDs), used by a single person for studying, have remained unchanged since the 1960s. Prior to this prototype all ISDs were basically a 
three-sided, dark-wood box, with a shelf on long legs with no lighting or electrical outlets. Chairs were wooden, built to last but not for comfort or adjustability. They were created in an era without online access or high use of technology by students.

\section{Problem or goal identification}

With changes in the technology and ways students study, the Lee Library undertook an effort to update their ISDs to improve the study experience for students (Zaugg, Belliston, \& Halverson, 2016).

\section{Communication}

The library's assessment office reached out to students using the old ISDs through a survey asking students what they liked about the desk and what changes they would like made to the desk. Using this survey, other students participating in a creativity, innovation, and design boot camp collected further input from ISD users and created three new ISD models as the prime focus of their course.

\section{Create the prototype}

Building on this information, a design team combined features of the three models from the student creativity boot camp to make two prototype ISDs. The main changes of the prototype ISDs included about twice the desktop space, a white board, a solid bar for a footrest, electrical outlets for technology, longer sides to prevent encroachment into an adjacent study space, and two types of lighting. On one prototype there was a glass half-wall with a solid half-wall on the other prototype.

\section{Evaluate and revise}

Both prototypes were displayed in the main entrance foyer of the library for 2 days where assessment personnel asked students passing by to examine and comment on the prototype desks. Following these 2 days of assessment, the prototype desks were rotated through several study areas in the library for patrons to use. During the 2-day exposure and the desk rotations, students were asked to complete a survey indicating the features they liked and disliked about the new ISDs. They also had the opportunity to suggest changes to improve the ISD.

Following these assessments, changes were made to improve the ISDs based on the recommendations. The solid footrest bar was replaced with a movable wedge footrest. Instead of a corner shelf and fluorescent lighting, a long shelf with an LED light was installed. Students requested the largest white board possible and, along with an electrical plug and light switch, USB plugs were installed. Following these changes, the original assessment process was repeated ( 2 days displayed in the main foyer followed by placement in three different study areas). The assessment indicated that the new ISD fit the needs of students and it was put into production with the old ISDs being gradually replaced by the new ISDs. 


\section{Celebrate success and failure}

After 2 years, with about half of the ISDs being old and half new, a follow-up assessment was conducted to determine if the new ISDs were better or just different. The assessment indicated that students studied for $60-90 \mathrm{~min}$ longer in the new ISDs. They felt happier and more comfortable, and about $90 \%$ of those using the new ISDs used the whiteboard to assist their studies. In this instance the prototypes led to a quick revision and a successful implementation of an improved study space for students.

\section{Combined circulation/help desk}

The main north entry of the Lee Library has two service points, a circulation desk (to the left as one enters) and a reference help desk (to the right in the entrance to the Learning Commons). Both desks were somewhat hidden from patrons entering the building. They also created a problem for patrons not knowing which desk was best for their service or information needs.

\section{Problem or goal identification}

In an effort to improve service and visibility, library leadership decided to combine the two desks into a single service point. However, they were uncertain of the best location for the combined desk and what would be the best configuration for the service point.

\section{Communication}

Discussions with non-student circulation desk employees helped us to determine that two sets of prototypes were needed. In designing the prototypes, these discussions continued and configurations that were not part of the original plan were considered. During each set of prototypes, formal and informal interviews with desk employees (non-student and student) and consultations via surveys helped determine the best location and configuration for the combined circulation/help desk.

\section{Create the prototype}

Through these consultations library leaders realized that two sets of three prototypes were needed. The first set of prototypes identified the best location, by setting up prototype desks in three locations, each for a week. The second set of prototypes examined three configurations, again each for a week. In each instance desk employees tried to simulate work flows and processes that occurred at both desks. The first set of prototypes helped to further develop the look and feel of the second set of prototypes as well as the evaluation procedures.

\section{Evaluate and revise}

Prototyping occurred over several weeks and the types of prototypes were pre-determined because of the complexity of arranging each prototype. The expense of building 
temporary counter space and the time needed to move materials was also part of the prototype plan. It was important to have as many of the combined services at each location and with each configuration as possible to accurately simulate the combined desk services. As a result each prototype in each set was rather complex. The location prototypes included three areas, one of which only part of the stakeholders wanted to assess. However, it was important to conduct a prototype using the space so it could be evaluated as being the best location or not. The first set of prototypes were conducted before the summer terms so the full student body could provide feedback. The prototypes included temporary counters with computer stations and book carts for quick access to the books on hold. Where possible all services were moved to the combined space, but some books were kept in their original area instead of being placed on book carts. If needed a library employee would return to the old area to retrieve the books.

During each of the first set of prototypes, a survey was used to collect feedback from patrons. Interviews of student and non-student staff regarding their impressions of each location were also collected. Assessment personnel also conducted observations of patron movement, including lines awaiting service at each desk and the impact of the desk location on patron movement during peak periods via video recordings. While the assessment of each location was helpful in deciding the final location, it also provided information on how to better collect data and organize the next set of prototypes. It also provided insights on where support services near the original desks (e.g., interlibrary loan) for the combined desk should be located.

Once the location for the new desk was determined, three prototypes were used to determine the desk configuration. The configurations included a square shaped desk without a hallway behind it, a square shaped desk with a hallway behind it, and a curved shaped desk without a hallway behind it. As with the location prototypes, each prototype was set up Monday through Thursday, with Friday designated as a day to switch to the new prototype. The look and completeness of each configuration was improved by using stationary shelving for all books to be located behind the desk, an employee work desk behind the counter, and curtains on the front of the counter to improve the esthetic appeal of the desk. These changes made each prototype look more formal and permanent than the previous set of prototypes. They more closely resembled what the final combined desk would look like.

Video data of movement patterns and interviews with library personnel working at the desk were collected during each prototype. Survey data from patrons regarding each prototype was not collected until the week after the last prototype. This allowed patrons to experience each prototype before commenting on them. To aid recollection of each prototype, schematics and images of each prototype were put on posters to help remind students of the prototype. One person was placed by the posters during the working hours of the day to ask patrons to provide feedback via iPads and an offline Qualtrics survey.

Just as the first round of prototypes indicated where the desk should be located, the second round indicated the best configuration for the combined desk. The prototypes informed not only the next prototype design but also how it would best fit in with other planned renovations and existing services. The first set of prototypes also informed us on how to better create and evaluate the second set of prototypes. The result is information for the final design of the combined desk. 


\section{Celebrate success and failure}

Each set of prototypes helped identify the best location and configuration of the combined desk. Stakeholders celebrated throughout the prototyping process, especially as we created each prototype. The prototypes not only informed the location and configuration of the desk but also served secondary purposes. They let us know where support services needed to be located. They informed patrons of the new location and configuration to prepare them for the upcoming change. They also helped student and non-student employees become more convinced that the change was needed and would be helpful. Working in the prototypes helped them to discover the advantages and note the little things that would improve service at the new locations.

\section{DVD collection}

The Lee Library has several thousand DVDs and VHS tapes in their collection. Initially all resources were housed behind the Media Center Help Desk and checkout was somewhat hampered by checkout policies. The majority of films in the Media Center collection were circulated for $4 \mathrm{~h}$ to students and couldn't leave the library. A few hundred DVDs in the Mormon Media Collection were circulated for 3 days to students. There was no ability by patrons to browse DVDs and videos as they were shelved by accession number. The only way to find these items was to search the library catalog by title, subject, or genre because they came to their spot on the shelf numbered in the order they arrived in cataloging.

\section{Problem or goal identification}

Spurred on by a desire to increase the circulation of these valuable yet relatively shortlived media, several prototypes were undertaken to improve the circulation of these items (Wilson, Frazier, \& Harter, 2015).

\section{Communication}

The prototypes involved a broad-based committee, the Media Center Coordinating Committee (MC3). It provided a broad representation from across the library, consisting of representatives from Public Services, Special Collections, Technical Services, the Library Administrative Office, and three representatives from outside the library whose departments use the Media Center collection most. MC3 members typically had unique interests and roles with the resources circulated by the Media Center. They considered changes to how media resources were circulated and policies that needed to be adjusted. In many instances, their recommendations were then forwarded to other leadership committees (Collection Management and Development Committee, and Administrative Council) for further input and final approval.

\section{Create the prototype}

Each prototype built on the learning and success of the previous prototype. Using a book cart, Media Center employees identified seasonal DVDs and videos and created a display for them in front of the Media Center Help Desk. For example, at Christmas, 
DVDs and videos with a Christmas theme were pulled from the collection and placed on the cart for a display. Each day the Media Center employees would notice that by the end of the day most, if not all, of the videos on the display were gone! This result encouraged them to pull more DVDs and videos from the collection to restock the display only to see a repeat of the first day. Although the assessment was informal, the fact that materials on display were quickly checked out could not be overlooked. For example, to determine how well the display helped DVDs get checked out, a foreign film DVD that had never been checked out before was displayed on the seasonal display rack. The DVD was checked out the day after it was displayed.

\section{Evaluate and revise}

More prototypes followed. More and more DVDs were displayed on the racks. Because there was a concern with the security of these items previously protected by being behind the desk, only the empty DVD cases were displayed. A patron interested in checking out the DVD would take the empty case to the desk and get the disc upon check out.

Following the success with the display, MC3 met to discuss further changes. Subsequent prototypes included identifying more DVDs and videos that could be put out on open stacks. Stacks from library surplus were used to extend the DVD display. A homegrown cataloging system was developed. The Media Center purchased security (locked and tattle-taped) cases for these materials. Upon checkout, the cases were unlocked and desensitized to allow them to go through the library security gates. While each kept their original ascension number, DVDs and videos were arranged alphabetically by title within each genre to assist browsing by patrons. Color coding and a separate spreadsheet helped to keep track of where DVDs and videos should be placed on shelves upon their return to the Media Center after patron use.

Statistics indicated a great increase in usage, so special DVD stacks were purchased and installed in the Media Center. All DVDs, including those already in open stacks and those still behind the desk, were placed in these open stacks. This reorganization was only accomplished with the help of the library's catalog department, who reclassified the DVD and Blu-rays to Library of Congress call numbers.

Concurrent with these changes, the Circulation Committee was investigating circulation policies in the library. Several Media Center circulation questions were added to their survey that was sent to other academic libraries. This action led to important improvements in the circulating policies of Media Center materials for students in the Harold B. Lee Library. The 4-h and 3-day check out of these material for students was replaced by a 7-day check out. The 2-week circulating period for faculty/staff and administrators was kept in place.

A video Film Finder link located on the main page of the library website was created. This Film Finder page uses a thumbnail image of each film. Films are easily accessed either by title in the search bar or by categories such as Popular for Checkout, New Arrivals for Checkout, Browse by Genre, and Popular Streaming Items and image links to Streaming Collections that the library subscribes to. Because it is patterned after the Redbox Kiosk displays, using Film Finder is quite familiar and useful to patrons. To 
further patron accessibility, an iPad already opened to Film Finder resides near the open stacks.

Subsequent prototypes included features like the employee pick of the month, recommended movies, and, of course, seasonal movie highlights continued. A media wall consisting of four large TV screens hangs on the wall as patrons enter the Media Center. Highlighted on each screen are very short clips of movies used by faculty in their classes, foreign films, animated films, seasonal films, and so forth.

With each change the circulation of the DVDs and videos were monitored. Compared to circulation prior to the changes brought on with each subsequent prototype, the circulation of DVDs more than doubled.

\section{Celebrate success and failure}

While subsequent years have seen a leveling off of DVD circulation, there was considerable celebration because more library resources were being used instead of languishing on shelves. The incremental prototypes helped library employees and patrons adjust to each change. It also offered insights into what could be done next. Though the MC3 is now disbanded, having accomplished its charge, Media Center employees continue to examine ways to highlight the materials and seek for changes that improve access to the DVDs and videos.

\section{Online tutorial}

In the spring of 2015, a new librarian was hired to oversee curriculum development for the library instruction portions of the university's first-year writing course, a course that teaches close to 5,000 students a year at BYU. After conducting surveys of students, librarians, and professors, as well as focus groups with these users, the librarian determined that the current model of instruction was not working as well as it could. Specifically, students were not coming to the library with enough context with which to fully utilize the help of the librarian instructors. A new curriculum model was developed that used the flipped classroom approach to teaching. A flipped classroom necessitates students learning content outside of class so that more time in class can be spent problem solving, modeling, and answering questions.

\section{Problem or goal identification}

With the goal of teaching more content outside of class and better preparing students to learn during library instruction periods, online tutorials were deemed the most productive way to disseminate information. This prototype sought to develop the online learning modules needed for a flipped-class instruction (Silva, 2017).

\section{Communication}

Communication among the production team was key in the success of the project. Before the project began in earnest, the librarian responsible for its creation approached 
key stakeholders, including the director of the writing programs at BYU, and sought advice about how best to elicit buy-in from professors who would be asked to use the products in their classrooms. With each major step in the process the director of the writing programs was consulted to make sure the project aligned with the major learning outcomes of the course. Later on, other stakeholders (i.e., professors and librarians) were asked to provide feedback.

\section{Create the prototype}

BYU's Y Search tutorials began production in the spring of 2016 and were rolled out as version 1.0 in the fall of 2016. The prototyping and testing phase lasted for 6 months. The initial team creating the tutorials consisted of the librarian content expert, an instructional designer, and a student employee.

The librarian acted as the scriptwriter and the instructional designer acted as the producer of the modules, with the student employee using the directions from both writer/ producer as the tutorials took shape. Each video tutorial was storyboarded to make sure the librarian was pleased with the content, animation, and special effects, and each interactive tutorial was modularized ahead of time to align with specific learning outcomes. This prototyping process allowed for daily back-and-forth communication between main members of the production team. The team used emails and frequent face-to-face meetings as they prototyped, revised, and tested the product.

\section{Evaluate and revise}

Once versions were ready to test, the librarian used library student employees as a test group and observed the usability and tested the learning outcomes of each tutorial. This group most clearly aligned with the eventual known users of the product. The librarian and student employees then used a rapid prototyping approach to make quick fixes and adjustments to the tutorials based on feedback, glitches, and other issues observed. The tutorials were then sent out to librarians and the same process was repeated. Finally the videos were sent to professors who repeated the same process with their students. Each of these groups: students, librarians, and professors represent a different kind of known user of the product.

Once the tutorials had been prototyped and tested with various groups, it was time for the final test group-two sections of a freshman composition class taking a summer term course. The librarian worked directly with the professors in these classes to integrate the modules and test student responses both in terms of satisfaction and learning outcomes. With student feedback, the modules were revised one last time before full rollout in fall of 2016. In the fall of 2016 there were over 100 sections of freshman composition that used the new modules at ysearch.byu.edu. To continue testing the effectiveness of the product, librarians persisted in rigorously surveying users during this period. More changes continued to be made with the addition of a fifth module in 2017.

\section{Celebrate success and failure}

In 2018 the website gained national attention when it won the Association of College and Research Libraries (a subsidiary of the American Library Association) Innovation in 
Instruction Award. As such, the production team realized that the user base of the product had expanded beyond BYU and embedded assessment links within the website itself (now visible on the fifth module). BYU-centered satisfaction surveys remain positive, with $64.7 \%$ of professors who use the product rating their satisfaction with the Y Search website a 5 out of 5 and another 29.4\% rating it a 4 out of 5 , totaling $94 \%$ of respondents that were either "very satisfied" or "satisfied" with the website's design, usability, content, and helpfulness as a learning tool.

\section{Collection evaluation}

Two motivations were behind this project and the prototypes associated with it. First, with over 6 million items in the library collection, many had become out-of-date or were still useful but rarely circulated. An evaluation process was needed to examine which resources could be removed, which could be moved to long-term storage, and which should remain on open stacks. Second, planned renovations in the library necessitated a review of these materials to create space for the renovations. The Lee Library science and engineering librarians were assigned the massive task to review over 350,000 print items for a mandated collection evaluation project. Within the department there were over 8,500 shelves of items to review. It was daunting in its magnitude.

\section{Problem or goal identification}

This collection evaluation project required (a) an effective and efficient process for evaluating and adjusting collections and (b) a process that could be scaled from a single librarian to the entire department (Nelson, Broadbend, Frost, Goates, \& Pixton, 2019).

\section{Communication}

In this project, communication had three separate phases. As the initial prototyping only involved the department chair for the library's Science and Engineering Department, communication was between him and the assistant facilities/project manager (FPM) and the stacks manager (SM). This communication dealt with what materials were needed and what services, via student employees, could be provided by the FPM and SM as together they prototyped the process to evaluate the science and engineering collection housed in the stacks and to move books once decisions were made.

Following the final successful prototype, the department chair explained and demonstrated the process to the other department librarians. This interaction allowed the process to be scaled to the entire department. It helped clarify the process and answer any questions librarians had. A final step in the communication process occurred between faculty and instructors in each academic department with their corresponding liaison librarian. In this instance, academic faculty members were asked to review items that were slated to be removed from the collection as a final review to ensure that items that were needed by faculty were not removed from the collection. 


\section{Create the prototype}

The initial prototyping efforts only involved one librarian, the chair of the Science and Engineering Department. The intent was to develop a process that could be scaled for all librarians within the Science and Engineering Department. Each item was identified according to predetermined criteria and physically reviewed to evaluate suitability to remain in the open stacks, to be sent to an onsite storage facility, or to be withdrawn from the library. Three iterations were necessary before settling on an efficient and productive process that was adopted by the entire department.

The librarian had a preliminary list of books on his computer that fit criteria for withdraw or long-term storage, but a physical review of each book was also necessary. A single bookcase, hereafter called a single facing unit (SFU), is composed of seven 35inch shelves ranging from 2 inches to 72 inches off the floor. It was a tedious, time-consuming, and frustrating process for the librarian to look up the appropriate call number on the computerized list and remember it as he looked for that particular book on the shelf, removed the book, marked its shelf location while the book was reviewed, made a decision, marked the book with either a pink/purple or yellow tag, marked the decision in the computer, and then finally moved on to the next item on the list. This process, as described, took between one to one and a half hours to do a single SFU.

\section{Evaluate and revise}

The first iteration was based on the need to physically examine each identified book and determine its eventual fate. The librarian placed a physical tag on each item that reflected a withdrawal or onsite storage decision that would be followed up with the books being pulled off the shelves and taken to a staging area. The FPM helped him identify which tags were the easiest and most efficient to use without damaging the book bindings.

This identification process was, itself, a sub-prototyping exercise. He initially used 3inch by 3 -inch sticky note pads that were completely sticky on one side and cut into four parallel strips. Tags were placed on the book's outer spine-pink tags, indicating withdrawal, and yellow tags, indicating onsite storage - and provided good contrast in the low-light conditions that sometimes prevailed amongst the bookshelves. However, over time some tags lost their stickiness and fell off. Two solutions presented themselves. Near the beginning of the project, the pink tags became no longer available commercially, so the project transitioned to purple painter's tape instead. The painter's tape adhered to the book better and was nondestructive to most of the bindings of books that were evaluated. The yellow sticky notes continued to be used to indicate books going to onsite storage, but shelvers placed the tag on the book perpendicular to the binding instead of attaching it parallel to the binding so that books on either side would provide enough pressure to keep the tag in place.

After only 2 days of using the list to manually search the shelf for each book with the appropriate call number on 12 SFUs, as described above, it was apparent that the process needed to be adjusted. One benefit to this process, however, was that the librarian was able to compare or review items on his respective lists with those that were to be kept on the open shelves. This method identified a major gap in the selection criteria 
that would not have been found and remedied if he had not been examining the items in context of the whole collection.

The second prototype revision focused on reducing the amount of time needed to review materials considering the large scope of the project. Fortunately, in the Lee Library students are hired to reshelf returned items after being processed. With the students' supervisors' approval and support, the librarian provided the shelvers a printed list of the materials to be reviewed and asked them to pull items from the bookshelves without adding colored tags, load them onto book carts with a designation for withdraw or onsite storage, and deliver them directly to his office. He evaluated the books one by one and placed them onto a withdrawal or onsite storage cart. Fully loaded carts with reviewed books were rolled outside his office where the shelvers then took them to a staging area.

This was a very convenient method for the librarian; however, he was dependent upon the shelvers delivering a fresh set of materials for evaluation to his office when he was ready for them. Sometimes he would have hundreds of books to review and at other times he was waiting for books to be delivered to his office, making it an inefficient process. A second disadvantage of this method was that the librarian lost the benefit of context to the breadth and depth of the collection's strength, having no comparison to the books that remained on the open shelves. The third disadvantage was that there was a finite number of book carts available for this project. The library was willing to rent carts from other libraries or third parties, but that would have increased the project expense and complexity. After several weeks of employing this methodology, it was abandoned and the third and last prototype revision of the process began.

The shelvers, who already had a print copy of the review criteria, were asked to leave the books in place on the shelves but affix the colored tags used previously to indicate withdrawal or relocation to the onsite storage site. This action allowed the librarian to go into the stacks and evaluate materials in their subject context whenever he had time. It also freed up the shelvers to tag an entire call number range and then move to other projects until the librarian needed a new section tagged. This method could also be easily scaled and done in parallel with the other members of the Science and Engineering Department and required no extra carts or other equipment.

With an efficient tagging method in place, an easy system to communicate to the shelvers which books could be removed from the shelves and which would remain was developed. When a section was tagged and ready for review, the shelvers would place a set of red and green laminated sheets together at the beginning of the section. The green sheet was printed with "Tagging Beginning" and indicated where shelvers should start removing tagged books. The red sheet was printed with "Reviewed to Here" and would be moved by the selector and placed just after the last book that had been reviewed, indicating that the shelvers should not remove items after that point. The green and red laminated pages extended half way out from the books like flags, clearly indicating which books within that section could be removed from the shelf and taken to the staging area.

Once the books had been pulled, the shelvers would move the green sheet next to the red sheet, which communicated to the subject selector where to continue reviewing materials. If shelvers had not come between several review sessions, the librarian would 
just continue to move the red sheet further and further down the line. This method had the advantage of allowing each subject librarian to review materials whenever they had time to do so, and also permitted the shelvers to work on a section according to their availability. One downside of this method was that occasionally a subject librarian would complete the review of a particular section and the shelvers would not have completed the tagging of the next area to be reviewed. In these instances the librarian would have to wait for that section to be tagged, but that was a rare occurrence.

\section{Celebrate success and failure}

With each prototype, those involved were able to learn from and adapt to the next prototype. The failures helped them learn what did and did not work on an individual and department level. The third iteration was the best process for the librarians to accomplish their work as quickly and efficiently as possible and allowed those who needed to tag and then remove materials after review to move at a pace and efficiency that met their needs. This process also allowed multiple subject librarians to work simultaneously without the need of multiple book carts or time wasted looking up each and every individual item by hand. Material evaluation could be done in a parallel instead of in a serial fashion, saving time, energy, and money. This process was developed by one person and the whole department benefited from his experience. It also allowed non-library faculty to begin to review identified lists of reviewed books.

The greatest success of this process is that eight subject librarians working in concert with the FPM, the SM, and their respective students were able to evaluate the 350,000 shelved items in just over 12 months. The result was an efficient and effective process that was easily scaled within the department and beyond. The collection evaluation process enabled renovation projects to begin as scheduled. Finally, several subject librarians indicated that the process helped them to become intimately acquainted with what was in their collection, ultimately helping non-library faculty and their students to better access and use library materials.

\section{Conclusion}

Prototypes offer a cost-effective and efficient means to revise library processes, develop library resources, and update library services. They are interim steps that promote the success and failures of each prototype towards a completed project. As noted in each example, failure was as important as success because it informed librarians on what worked and what needed to be changed. Continual communication and evaluation are critical elements that enable prototyping to be used to improve how things are done in the library. Prototypes offer ongoing insights for those interested in continual improvement in an efficient and effective manner.

\section{References}

Becksford, L., \& Metko, S. (2017, October). Inventing the future: Applying design thinking to NextGen program development (pp. 1-8). Proceedings of the Conference for Entrepreneurial Librarians, Greensboro, NC. 
Camere, S., \& Bordegoni, M. (2016). Unfolding the notion of experience (virtual) prototyping: A framework for prototyping in an experience-driven design process. Journal of Integrated Design and Process Science, 20(2), 17-30. doi:10.3233/jid-2016-0012

Chasanidou, D., Gasparini, A. A., \& Lee, E. (2015, July). Design thinking methods and tools for innovation (pp. 12-23). International Conference of Design, User Experience, and Usability, Springer, Cham, CH.

Chase, S. (2017). Design thinking in action: Changing the public service model. OLA Quarterly, 22(3), 15-19. doi:10.7710/1093-7374.1865

Coleman, M. C. (2016). Design thinking and the school library. Knowledge Quest, 44(5), 62-68.

Deitering, A., \& Filar-Williams, B. (2018). Make it work: Using service design to support collaboration in challenging times. International Information \& Library Review, 50(1), 54-59. doi: $10.1080 / 10572317.2017 .1422901$

Desrosier, J. (2011). Rapid prototyping reconsidered. The Journal of Continuing Higher Education, 59(3), 135-145. doi:10.1080/07377363.2011.614881

Ficzere, P., Borbás, L., \& Török, Á. (2013). Economical investigation of rapid prototyping. International Journal for Traffic and Transport Engineering, 3(3), 344-350. doi:10.7708/ijtte. 2013.3(3).09

Howard, Z., \& Davis, K. (2011). From solving puzzles to designing solutions: Integrating design thinking into evidence based practice. Evidence Based Library and Information Practice, 6(4), 15-21. doi:10.18438/B8TC81

Kohler, K., \& Hochreuter, T. (2014, October). Let's compare prototypes for tangible systems: But how and why? (pp. 323--332). Proceedings of the 8th Nordic Conference on HumanComputer Interaction: Fun, Fast, Foundational, New York, NY.

Lopez, S. M., \& Wright, P. K. (2002). The role of rapid prototyping in the product development process: A case study on the ergonomic factors of handheld video games. Rapid Prototyping Journal, 8(2), 116-125. doi:10.1108/13552540210420989

Lynn, G. S., \& Akgün, A. E. (2003). Launch your new products/services better, faster. ResearchTechnology Management, 46(3), 21-26.

Medlej, M., Stuban, S. M., \& Dever, J. R. (2017). Assessing the likelihood of achieving prototyping benefits in systems acquisition. Defense Acquisition Research Journal, 24(4), 626-655. doi:10.22594/dau.17-774.24.04

Meier, J. J., \& Miller, R. K. (2016). Turning the revolution into an evolution: The case for design thinking and rapid prototyping in libraries. College \& Research Libraries News, 77(6), 283-286. doi:10.5860/crln.77.6.9506

Neeley, W. L., Lim, K., Zhu, A., \& Yang, M. C. (2013, August). Building fast to think faster: Exploiting rapid prototyping to accelerate ideation during early stage design (pp. V005T06A022-V005T06A022). ASME 2013 International Design Engineering Technical Conferences and Computers and Information in Engineering Conference, American Society of Mechanical Engineers, Portland, OR.

Nelson, G. M., Broadbend, D., Frost, M. F., Goates, M. C., \& Pixton, D. (2019, May). Collection weeding: Breaking new ground with innovative processes and tools. Paper Presented at the 2019 Annual Utah Library Association Conference, Sandy, UT.

Schrage, M. (1999). Faster innovation? Try rapid prototyping. Harvard Management Update, $4(12), 10$.

Silva, E. (2017). Teaching first year students how to read online. Ubiquitous Learning: An International Journal, 10(3), 11-17. doi:10.18848/1835-9795/CGP/v10i03/11-17

Wilson, D., Frazier, C., \& Harter, D. (2015). Circulation policies in major academic libraries. Journal of Academic Librarianship, 41(6), 798-803. doi:10.1016/j.acalib.2015.08.019

Zaugg, H., Belliston, J., \& Halverson, T. (2016, October-November). Design and assessment of new individual study carrels. Poster presented at the meeting of the Library Assessment Conference, Arlington, VA. 